\title{
Observation of Aggregate Structure of Green and Blue Fluorescent Powders Suspended in Heptane by Interactive Force Measurement
}

\author{
Akira OTSUKI ${ }^{a}$, Jun SADAKI ${ }^{a}$, Kunihiko YAMAGUCHI ${ }^{b}$, \\ Atsushi SHIBAYAMA ${ }^{\mathrm{b}}$ and Toyohisa FUJITA ${ }^{\mathrm{a}}$ \\ a Department of Geosystem Engineering, The University of Tokyo, \\ 7-3-1, Hongo, Bunkyo-Ku, Tokyo, 113-8656, Japan. \\ ${ }^{b}$ Faculty of Engineering and Resource Sciences, Akita University, \\ 1-1, Tegatagakuen-Cho, Akita, 010-8502, Japan.
}

\begin{abstract}
Three kinds of fluorescent powders were separated by means of organic liquid-liquid extraction for the recycling purpose. The effect of surfactant concentration on the separation of the fluorescent powders was observed. In this study, the effect was analyzed by observing aggregate structure of the green and blue fluorescent powders using an experimental apparatus, which measured the interactive force between two surfaces of glass hemisphere and flat plate under electric field. The maximum distance between two surfaces is $20 \mu \mathrm{m}$. The size of aggregates and adsorption state of green and blue fluorescent powders in heptane containing a certain amount of surfactant was measured. This method would be very useful for measuring the size of aggregate and the adsorption state of ultra fine particles dispersed in solution.
\end{abstract}

Key Words : aggregate size; adsorption state; fluorescent powder; heptane; interactive force measurement

\section{INTRODUCTION}

Red, green and blue fluorescent powders, which contain lots of rare earth metals have been recovered for the recycling purpose ${ }^{1)}$. The powders are generally used for fluorescent light ${ }^{2)}$. Although non-thermal extraction methods by acidic leaching have been reported $^{3,4)}$, these methods need further steps for extraction from acidic solutions and energy. Therefore, a material recovery method to obtain higher purified fluorescent powders is required for the recycling. Due to the fine particle size (less than $3 \mu \mathrm{m}$ ) and high similarity of the physical properties of the fluorescent powders, conventional separation techniques, such as flotation, is not suitable for the recovery of the powders ${ }^{5}$. Liquid-liquid extraction method was chosen to separate each fluorescent powder from a mixture of the three kinds of powders ${ }^{1)}$. During the extraction method, green powder is first extracted into heptane phase, separating from the other red and blue powders and then the others remained in N,N-dimethyl formamide (DMF) are separated each other. Surfactant concentration is very important on the separation results.

In this study green and blue fluorescent powders, separated at the first extraction step, are used as sample powders. Heptane and dodecyl amine acetate (DAA) are used as organic phase and surfactant. The extraction into heptane-DMF interface by the hydrophobic aggregation of green or blue fluorescent powders adsorbing dodecyl amine of DAA, is investigated for the mechanism study of the extraction. For that purpose, the coagulation models of the fluorescent powders during liquid-liquid extraction were proposed. In order to confirm the validity of the models, we have also developped a laboraotry-scaled apparatus in order to measure the interactive force between representative two powders in electric field ${ }^{6}$. This appratus measured the interactive force among many particles suspended in solution. That is the primary difference between conventional interactive force measurement ${ }^{7)}$ and our appratus. The measurement is conducted within the range from nanometer to micrometer order by analyzing a significant change of interactive free energy between hemisphere and flat plate. The cycle of change occurred expresses an aggregate size and the particle aggregation means the particles are extracted to the heptane-DMF interface by the hydrophobic coagulation after coating surfactant on the particles.

\section{MATERIALS}

\subsection{Fluorescent powders}

Fluorescent powders containe of a large amount of rare earth metals as shown in Table 1. In this study, green and blue fluorescent powders were used as sample powders. Physical characteristics of two fluorescent powders in terms of zeta potential, particle size (green: $1.11 \mu \mathrm{m}$; blue: $2.06 \mu \mathrm{m}$ ) and density (green: $5060 \mathrm{~kg} / \mathrm{m}^{3}$; and blue: $4270 \mathrm{~kg} / \mathrm{m}^{3}$ ) were quite similar $^{1)}$. These characteristics were important factors for physical separation techniques.

\subsection{Surfactant}

Surfactant used in this experiment was DAA (Dodecylamine Acetate, $\mathrm{C}_{12} \mathrm{H}_{25} \mathrm{NH}_{2} \mathrm{CH}_{3} \mathrm{COOH}$ ) as a cationic surfactant, which produced dodecyl amine to separate green fluorescent powder from other blue and red fluorescent powders. 
Table 1 Chemical compositions of fluorescent powder samples.

\begin{tabular}{lcr}
\hline Powder (Formula) & Component & Content $(w t \%)$ \\
\hline Red $\left(\mathrm{Y}_{2} \mathrm{O}_{3}: \mathrm{Eu}^{3+}\right)$ & $\mathrm{Y}_{2} \mathrm{O}_{3}$ & 91.6 \\
& $\mathrm{Eu}_{2} \mathrm{O}_{3}$ & 7.8 \\
\hline & $\mathrm{P}_{2} \mathrm{O}_{5}$ & 29.8 \\
Green $\left(\mathrm{LaPO}_{4}: \mathrm{Tb}^{3+}, \mathrm{Ce}^{3+}\right)$ & $\mathrm{La}_{2} \mathrm{O}_{3}$ & 39.7 \\
& $\mathrm{CeO}_{2}\left(\mathrm{Ce}_{2} \mathrm{O}_{3}\right)$ & $18.8(17.9)$ \\
& $\mathrm{Tb}_{4} \mathrm{O}_{7}\left(\mathrm{~Tb}_{2} \mathrm{O}_{3}\right)$ & $10.3(10.1)$ \\
\hline & $\mathrm{P}_{2} \mathrm{O}_{5}$ & 25.0 \\
& $\mathrm{Al}_{2} \mathrm{O}_{3}$ & 1.3 \\
$\mathrm{Clue}\left((\mathrm{Sr}, \mathrm{Ca}, \mathrm{Ba})_{10}\left(\mathrm{PO}_{4}\right)_{6} \mathrm{Cl}_{2}: \mathrm{Eu}^{2+}\right)$ & $\mathrm{Cl}^{2+}$ & 1.1 \\
& $\mathrm{CaO}_{2} \mathrm{O}_{3}$ & 1.8 \\
& $\mathrm{SrO}$ & 0.014 \\
& $\mathrm{BaO}$ & 41.2 \\
& $\mathrm{Eu}_{2} \mathrm{O}_{3}(\mathrm{EuO})$ & 27.0 \\
& & $1.1(1.0)$ \\
\hline
\end{tabular}

\subsection{Organic solvent}

Employed organic solvent was heptane $\left(\mathrm{CH}_{3}\left(\mathrm{CH}_{2}\right)_{5} \mathrm{CH}_{3}\right)$, which was most appropriate solvent to extract fluorescent powders.

\subsection{Experimental conditions}

Previous study showed that by adding optimum amount of DAA $\left(2 \times 10^{-4} \mathrm{~mol} / \mathrm{L}\right)$ each of the fluorescent powders was separated at more than $90 \%$ recovery and grade ${ }^{1)}$. At each measurement, one kind of fluorescent powders $(0.1 \mathrm{~g})$ was dispersed in $10 \mathrm{~mL}$ heptane solution with $\left(2 \times 10^{-4} \mathrm{~mol} / \mathrm{L}\right)$ or without DAA $(0$ $\mathrm{mol} / \mathrm{L})$ in order to investigate the effect of surfactant addition on aggregate size of the green and blue fluorescent powders.

\section{INTERACTIVE FORCE MEASUREMENT}

\subsection{Experimental setup}

The experimental setup for measuring the interactive force between two surfaces, gold-coated glass hemisphere and brass flat plate was shown Figure 1. It had three parts, i.e., main part (electric balance, hemisphere and flat plate), control part (personal computer and piezo-stage controller), and detecting part (multi-meter and oscilloscope). The main part measured the weight of a hemisphere stated in sample solution with decreasing the distance between the two surfaces at the distance period of 100 $\mathrm{nm}$. The control part set supply voltage, regulated a piezo-stage movement and collected data from the balance and the piezo-stage controller. The detecting part measured the contact point where the hemisphere and flat plate attached. Interactive force was measured between the two surfaces containing sample solution in the cell. When the gap was quite small, an interactive force acted between the flat plate and the hemisphere. Consequently, the effective weight of the hemisphere hung on the electric balance changed. Its change was measured by the balance.

The movement of piezo-stage was used to regulate the distance between the hemisphere and flat plate (Figure 2). Detecting the contact point where the hemisphere and flat plate at the bottom of the cell attached, i.e. the surface distance was zero, was quite significant for calculating the surface distance. Following, two methods were proposed for determining the contact point. The first method measured the sudden change of the resistance of the circuit of the experimental setup. The second method consisted of measuring the voltage, which was converted from the force acting on the flat plate.

\subsection{Experimental procedure}

Schematic image of forces acting on two particles in the electric field is shown in Figure 3. The polarization $\boldsymbol{P}$ of material is shown in equation (1).

$$
\boldsymbol{P}=\chi_{\mathrm{e}}\left(\varepsilon_{0} \boldsymbol{E}\right)
$$

Where $\chi_{e}, \varepsilon_{0}$ and $\boldsymbol{E}$ refer to polarizability, space permeability and an external electric field, respectively. The intensity of polarization of spherical particle (volume $V$ ) is $\boldsymbol{P} V / 3$. Here the polarization is assumed to locate in the center of spherical particle. The angle between the electric field direction and the line connecting the centers of two spherical particles is $\theta$ and the distance between the centers of two spherical particles is $r$. The force to electric field

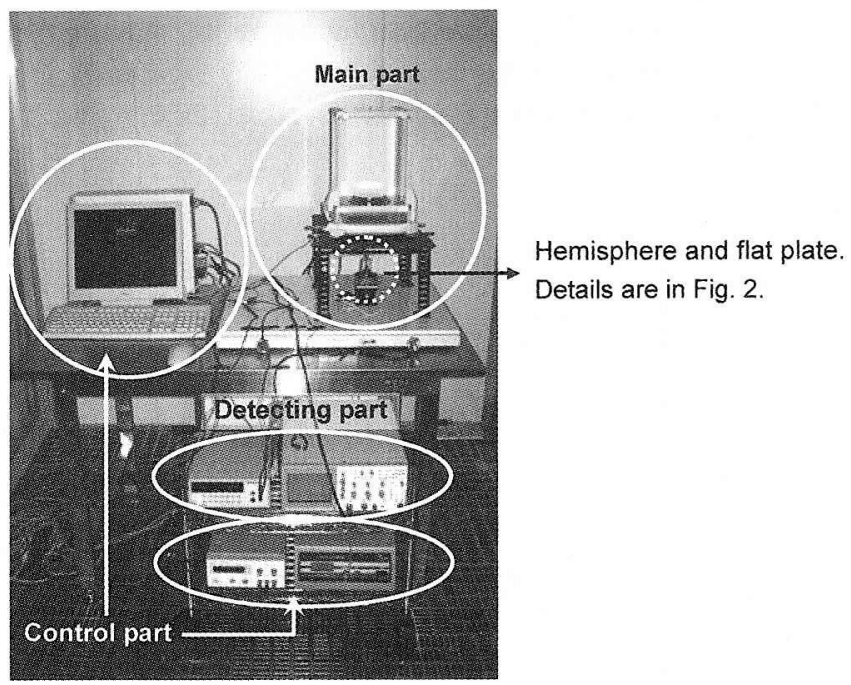

Figure 1 Photograph of experimental setup for interactive force measurement.

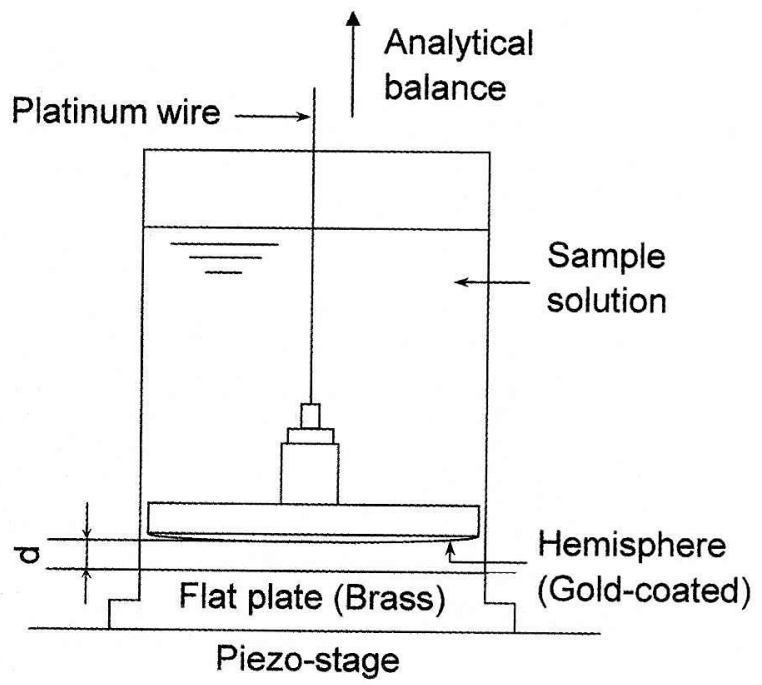

Figure 2 Schematic diagram of main part of the experimental setup for interactive force measurement. 
$\boldsymbol{F}_{y}$ and the vertical direction force to the electric field $\boldsymbol{F}_{x}$ are described in the following formula.

$$
\begin{aligned}
& \boldsymbol{F}_{y}=-\frac{1}{4 \pi \varepsilon_{0}} \frac{3(\boldsymbol{P} V / 3)^{2}}{r^{4}} \times\left[\left(3 \cos \theta^{2}-1\right) \cos \theta-\sin \theta \sin 2 \theta\right] \\
& \boldsymbol{F}_{x}=\frac{1}{4 \pi \varepsilon_{0}} \frac{3(\boldsymbol{P} V / 3)^{2}}{r^{4}} \times\left[\left(3 \cos \theta^{2}-1\right) \sin \theta+\cos \theta \sin 2 \theta\right]
\end{aligned}
$$

Figure 4 indicates behavior of particles dispersed in sample solution between the hemisphere and flat plate. Particles are suspended, whereas they are arranged toward the direction of electric field by applying an external electric field $\boldsymbol{E}$ (step 1). Following the electric field is applied, the flat plate moves close to the hemisphere, thus a repulsive force works against the compressive force (step 2). Then, the particle that can not support the effect of compressive force are pushed out. On the other hand, the attractive force at a hole where the particle is pushed out appeared (step 3). Following that, rearrangement of particles is carried out by the dielectric polarization and forces described in Figure 3 (steps 4 and 5). Consequently, the repulsive force appears again (step 6). Thus the repulsive and attractive force repeatedly appear. The cycle from attractive to repulsive is supposed to be size of the particle, which is measured. The behavior of many particles existened in actual fluid would be

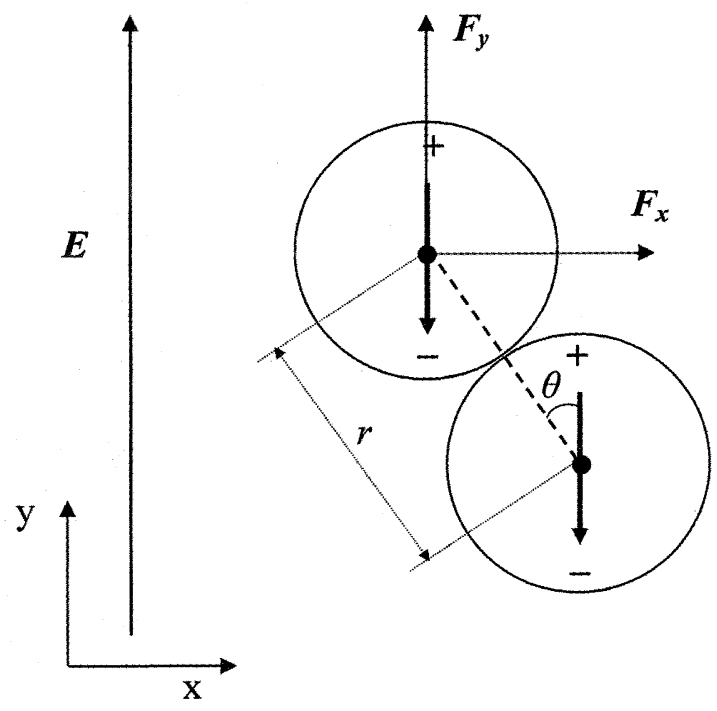

Figure 3 Schematic diagram of forces acting on two particles in the electric field. described as the similar phenomena.

The interactive force within nm order distance is changed to the interactive free energy using the Derjaguin equation ${ }^{8}$ :

$$
W_{(D) \text { plane }}=\frac{F_{(D) \text { sphere }}}{2 \pi R}
$$

where $W_{(D) \text { plane }}, F_{(D) \text { sphere }}$ and $R$ refer to the interactive free energy, the interactive force between the hemisphere and the flat plate, and the curvature radius of the glass hemisphere, respectively.

\section{RESULTS AND DISCUSSION}

Behavior of fluorescent powders during the liquid-liquid extraction is described in Figure 5. Previous study showed that the concentration of surfactant addition changed the recovery and grade of the fluorescent powders ${ }^{1)}$. The mixture of green, blue powders remained in the DMF phase when the extraction was performed without DAA (Figure 5 (a)). However, when the DAA was added in heptane, only green fluorescent powders adsorbing dodecyl amine of DAA became hydrophobic and coagulated, moving toward the heptane-DMF interface (Figure 5 (b)).

Zeta potential of the fluorescent powders were measured by means of Electrophoretic Light Scattering Spectrophotometer (Otsuka Electronics Co. Ltd., Japan, ELS8000) as shown in Figure 6. Zeta potential of green and blue powders were high negative without addition of DAA ( $0 \mathrm{~mol} / \mathrm{L}$ of DAA $)$. Therefore, both the green and blue powders were not easy to aggregate. With increasing the addition of DAA, zeta potential of the fluorescent powders was decreased. In the case of green powder, zeta potential of the green powder was small negative with addition of $2 \times 10^{-4}$

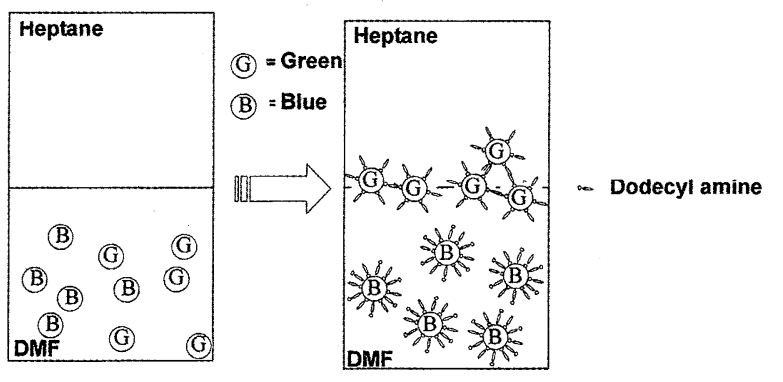

(a)

(b)

Figure 5 Behavior of green and blue fluorescent powders during the liquid-liquid extraction without DAA (a) and with DAA (b).

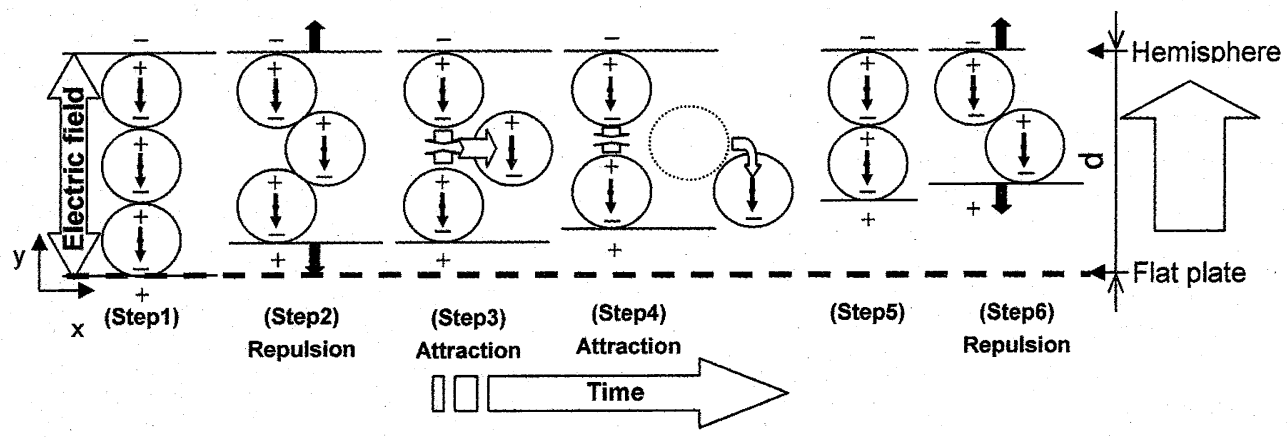

Figure 4 Schematic diagram of behavior of particles dispersed in sample solution between the hemisphere and flat plate. 
mol/L of DAA. Then, particles of the green powder was easy to aggregate because of outer surface of green powder is hydrophobic for the DAA adsorption. In the case of blue powder, however, zeta potential of the blue powder was positive value due to the hemimicelle formation of DAA with addition of $2 \times 10^{-4} \mathrm{~mol} / \mathrm{L}$ of DAA. Then, particles of the blue powder was not easy to aggregate becuase of outer surface of blue powder is hydrophilic for hemimicell formation of DAA. From the above results, at $2 \times 10^{-4} \mathrm{~mol} / \mathrm{L}$ of DAA only green fluorescent powders became hydrophobic, moving toward the heptane-DMF interface.

Differences between zeta potential values of the green and blue powders were due to their chemical compositions as listed in Table 1. While main compositions of the green powder are trivalent element, such as $\mathrm{La}^{3+}, \mathrm{Ce}^{3+}$, and $\mathrm{Tb}^{3+}$, ones of the blue powder are bivalent element, such as $\mathrm{Sr}^{2+}, \mathrm{Ba}^{2+}$ and $\mathrm{Eu}^{2+}$. The green powder has more negative charge than the blue powder if the surface of the green powder has defects.

In order to observe effect of the surfactant on separating green fluorescent powder from the others, the interactive free energy was assessed. Figures 7 and 8 show the variation of the interactive free energy between the glass hemisphere and flat plate in heptane dispersing green and blue fluorescent powder with or without DAA under 1.0 voltage supply, respectively. In Figure 7, there were some peaks showing that approximately $5 \mu \mathrm{m}$ cycles of attractive and repulsive forces only when $2 \times 10^{-4} \mathrm{~mol} / \mathrm{L}$ of DAA was added in heptane containing green fluorescent powder. Based on our model of behavior of particles during interactive force measurement (Figure 4), it was found that approximately $5 \mu \mathrm{m}$ aggregates of green fluorescent powder were formed while DAA was added. On the other hand, the results measured without DAA $(0 \mathrm{~mol} / \mathrm{L})$ showed very smooth curves. The few aggregates of the green fluorescent powder were formed without DAA.

In case of dispersing blue fluorescent powder in heptane, the interactive force measurement, both with $\left(2 \times 10^{-4} \mathrm{~mol} / \mathrm{L}\right)$ and without $(0 \mathrm{~mol} / \mathrm{L})$ DAA addition, generated smooth curves (Figure 8). It was found that the aggregate of blue fluorescent powder was not formed even when DAA was added. That was the difference between green and blue particles suspension.

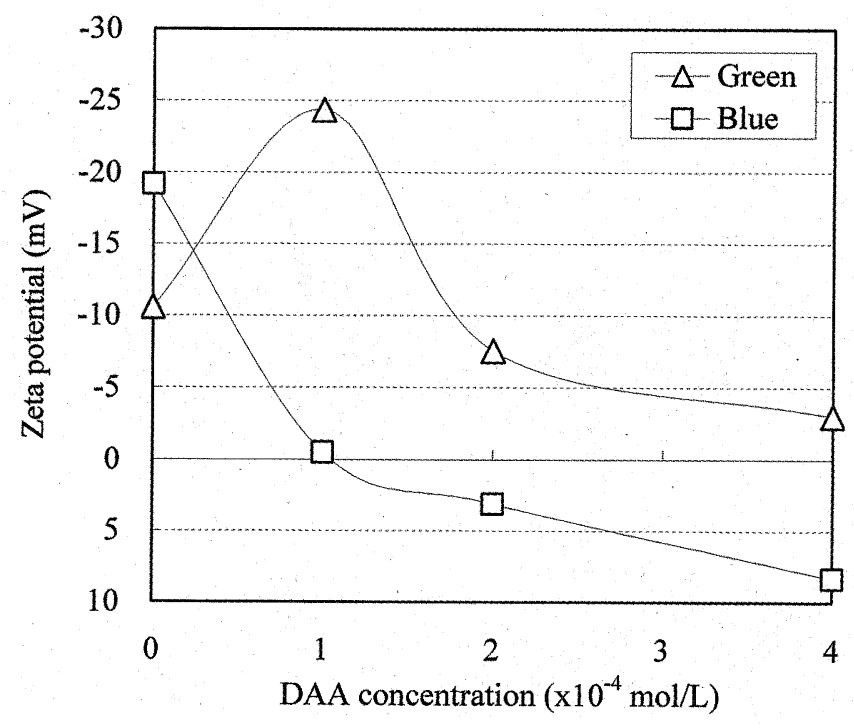

Figure 6 Zeta potential of fluorescent powders inside n-heptane as a function of DAA concentration.
In order to further clarify the data obtained by interactive force measurement, differentiating the data shown in Figures 7 and 8 with respect to time provided Figures 9 and 10 for the green powder and the blue powder, respectively; since the peaks shown in Figures 7 and 8 were slightly unclear to define aggregate size of the fluorescent powders. Interactive free energy was always negative as a function of surface distance both in Figures 7 and 8. Therefore, the place where value of differentiated interactive free energy was from negative to positive was the place where attractive force was occurred during the interactive force measurement. Distance between two peaks, which had positive value, was supposed to be the aggregate size of the fluorescent powder. From the above operational procedure, aggregate sizes of the green powder with DAA was observed $(8.0 \mu \mathrm{m}$ and $2.0 \mu \mathrm{m})$

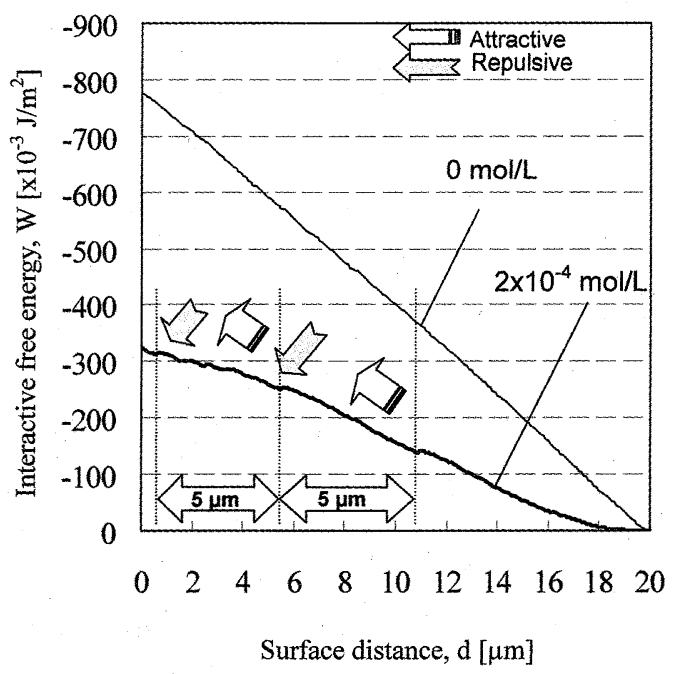

Figure 7 Interactive free energy between the glass hemisphere and the brass flat plate in heptane dispersing green fluorescent powder with $\left(2 \times 10^{-4} \mathrm{~mol} / \mathrm{L}\right)$ or without DAA $(0 \mathrm{~mol} / \mathrm{L})$ with voltage supply $(1.0 \mathrm{~V})$.

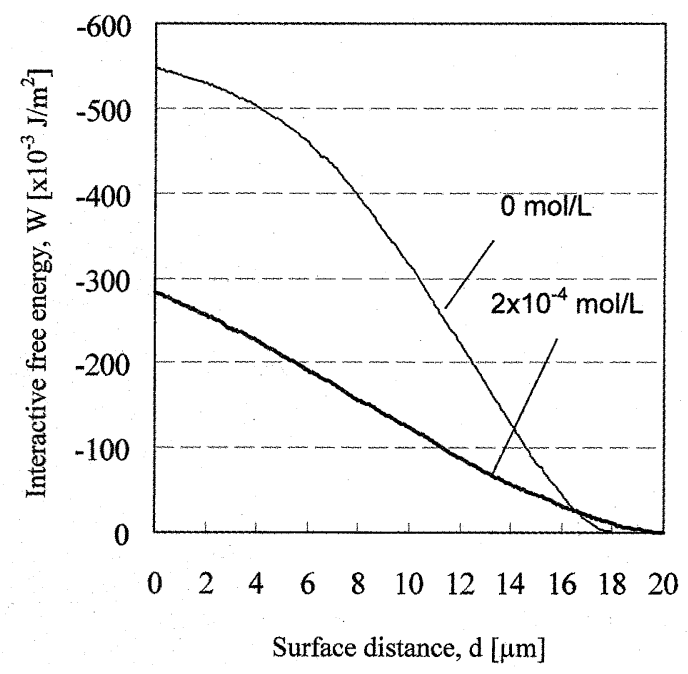

Figure 8 Interactive free energy between the glass hemisphere and the brass flat plate in heptane dispersing blue fluorescent powder with $\left(2 \times 10^{-4} \mathrm{~mol} / \mathrm{L}\right)$ or without DAA $(0 \mathrm{~mol} / \mathrm{L})$ with voltage supply $(1.0 \mathrm{~V})$. 
while no more than two peaks was observed at the measurement without DAA (Figure 9). Difference between two results on Figure 9 was caused by DAA addition to the heptane solution. DAA covered particles of the green powder, made the particles hydrophobic. Those hydrophobic particles aggregated with the other hydrophobic particles. The aggregates were observed at measurement of the green powder with DAA of $2 \times 10^{-4} \mathrm{~mol} / \mathrm{L}$. On the other hand, Figure 10 shows that value of differentiated interactive free energy of the blue powder both with and without DAA was always negative. In this case, DAA acted as dispersant for the blue powder and prevent the blue powder from aggregating each other.

In order to verify the results of interactive force measurement, relationship between surface free energy of heptane-DMF interface and diameter of the particles of green fluorescent powder was evaluated. By assuming two liquids were not dissolved each other, surface free energy of the two liquid interface was provided

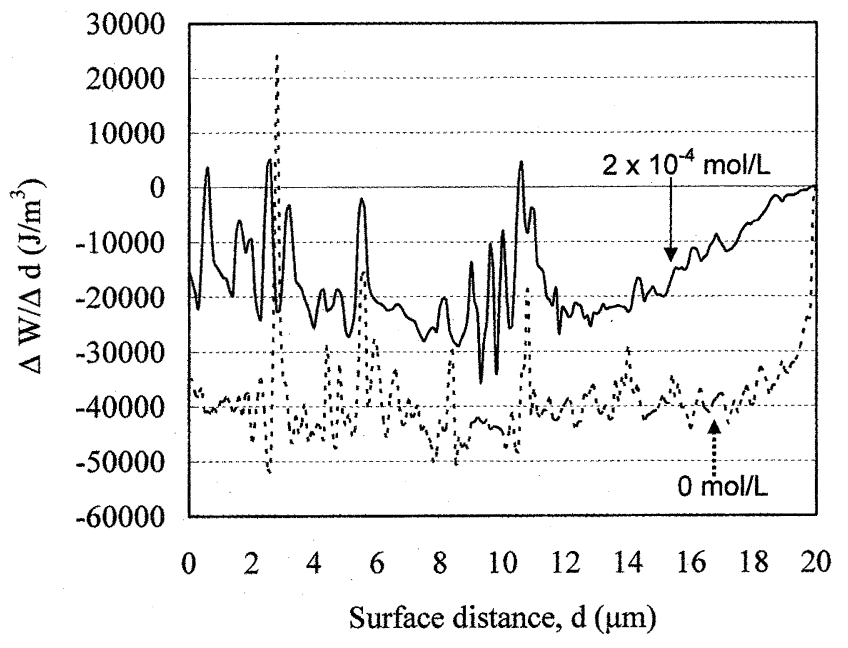

Figure 9 Differentiated interactive free energy in heptane dispersing green fluorescent powder with $\left(2 \times 10^{-4} \mathrm{~mol} / \mathrm{L}\right)$ or without DAA $(0 \mathrm{~mol} / \mathrm{L})$.

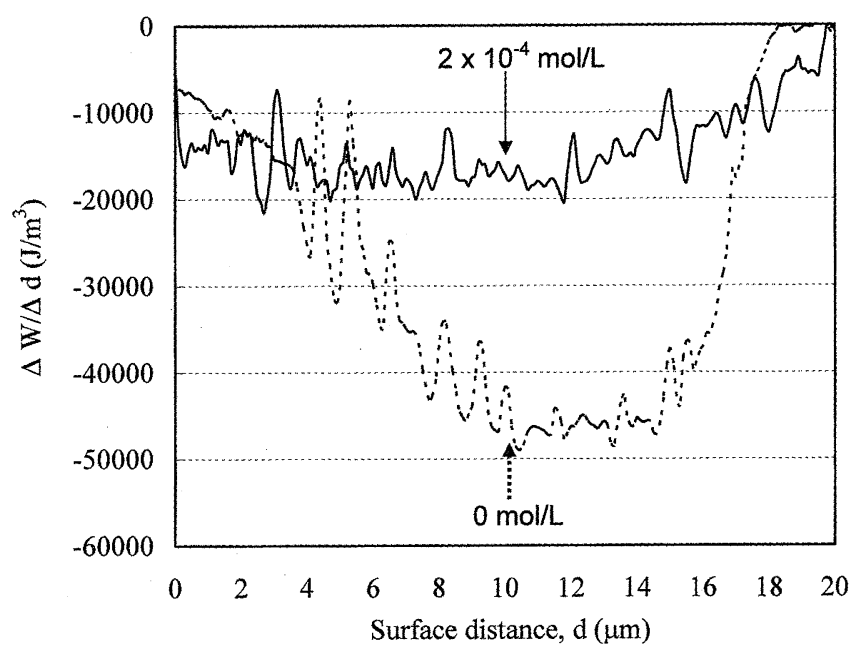

Figure 10 Differentiated interactive free energy in heptane dispersing blue fluorescent powder with $\left(2 \times 10^{-4} \mathrm{~mol} / \mathrm{L}\right)$ or without DAA $(0 \mathrm{~mol} / \mathrm{L})$. as follows ${ }^{9}$ :

$$
\gamma_{12}=\left|\gamma_{1}-\gamma_{2}\right|
$$

where $\gamma_{12}, \gamma_{1}, \gamma_{2}$ refer to surface free energy of interface of liquid 1 and liquid 2, surface free energy of liquid 1 (DMF: $35.2 \times$ $10^{-3} \mathrm{~J} / \mathrm{m}^{2}$ ) and surface free energy of liquid 2 (Heptane: $17.9 \times$ $10^{-3} \mathrm{~J} / \mathrm{m}^{2}$ ), respectively ${ }^{10)}$. Surface tension of the particle of the fluorescent powder at the boundary of two liquids was calculated as follows:

$$
\sigma(a)=\frac{M g}{2 \pi a}=\frac{V\left(\rho-\rho^{\prime}\right) g}{2 \pi a}=\frac{\frac{4}{3} \pi a^{3}\left(\rho-\rho^{\prime}\right) g}{2 \pi a}=\frac{2}{3}\left(\rho-\rho^{\prime}\right) g a^{2}(6)
$$

where $M, g, a, V, \rho, \rho^{\prime}$ refer to weight, gravity acceralation, radius of the particle, volume of the particle, density of the particle and average density of fluids, respectively. Combining Eqs. (5) and (6), difference between surface free energy of the two liquid interface and force caused by weight of the particle was calculated:

$$
\gamma_{12}-\sigma(a)=\left|\gamma_{1}-\gamma_{2}\right|-\frac{2}{3}\left(\rho-\rho^{\prime}\right) g a^{2}
$$

Solving Eq. (7) found that size of the aggregate of the green fluorescent powders supported by surface free energy of heptaneDMF interface as shown in Figure 11. When $\gamma_{12}-\sigma(a)$ was positive, heptane-DMF interface could support the aggregates of the powder hanging on the interface. When $\gamma_{12}-\sigma(a)$ was negative, heptane-DMF interface could not support the aggregates hanging on the interface and then the aggregates dropped into the DMF phase. Figure 11 indicated that surface free energy of heptane-DMF interface could support aggregate having less than about $1600 \mu \mathrm{m}$ in size. By considering the measured aggregate size of the green powder by interactive free energy, the aggregate size $(8.0 \mu \mathrm{m}$ and $2.0 \mu \mathrm{m})$ was below the calculated value, which surface free energy of heptane-DMF interface could support. Therefore, the aggregate of the green powder was trapped by the surface free energy of the heptane-DMF interface as described in Figure 5.

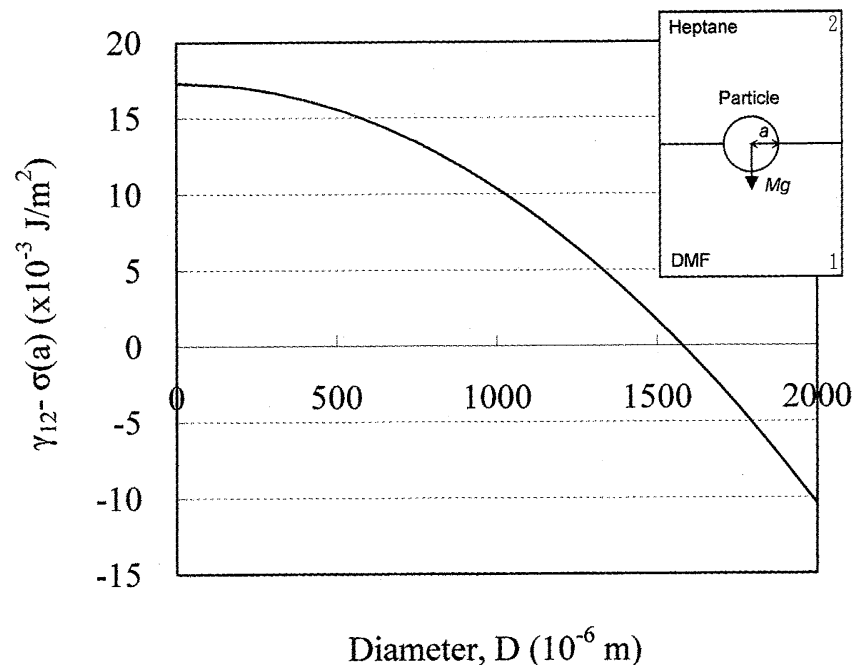

Figure 11 Relationship between surface free energy of $n$-heptane-DMF interface and diameter of the particles of green fluorescent powder. 


\section{CONCLUSIONS}

The effect of adsorbing surfactant on the extraction into heptane phase by the hydrophobic coagulation of green and blue fluorescent powders was investigated using our experimental apparatus. The apparatus measured the interactive force acting between glass hemisphere and flat plate, filled with heptane containing one kind of fluorescent powder and surfactant. The measurement was carried out with a low supply voltage $(1.0 \mathrm{~V})$. The size of aggregates of green fluorescent powder in heptane containing $2 \times 10^{-4} \mathrm{~mol} / \mathrm{L}$ of DAA was measured approximately $5 \mu \mathrm{m}$ by the measured curves. In order to further clarify the data obtained by interactive force measurement, differentiating the data obtaned by the measurement with respect to time gave that the aggregate size of the green powder was $8.0 \mu \mathrm{m}$ and $2.0 \mu \mathrm{m}$. Also calculation of surface free energy of heptane-DMF interface showed that measured aggregate size of the green powder was smaller than that of aggregate could be supported by the surface free energy. From the above results, the proposed model of aggregate structure of the fluorescent powders during the extraction was confirmed. As an extraction, hydrophobic green aggregates with dodecyl amine of DAA and was then moved toward the heptane-DMF interface. That let the green fluorescent powder be separated from other powders, which were not aggregated with dodecyl amine in heptane.

\section{ACKNOWLEDGMENT}

The present work was supported through the $21^{\text {st }}$ Century COE Program, "Mechanical Systems Innovation," by the Ministry of Education, Culture, Sports, Science and Technology.

\section{NOMENCLATURE}

$a$

$D \quad$ diameter of the particle

(m)

(m)

$(\mathrm{V} / \mathrm{m})$

$F_{(D) \text { sphere }}$ interactive force between the hemisphere and the flat plate

$(\mathrm{J} / \mathrm{m})$

$F_{x} \quad$ vertical direction force to the electric field

$(\mathrm{J} / \mathrm{m})$

$F_{y} \quad$ force to the electric field

$(\mathrm{J} / \mathrm{m})$

$g \quad$ gravity acceralation $\left(g=9.81 \mathrm{~m} / \mathrm{s}^{2}\right)$

$\left(\mathrm{m} / \mathrm{s}^{2}\right)$

weight

$(\mathrm{kg})$

$P \quad$ polarization of material

$R \quad$ curvature radius of the glass hemisphere

$\left(\mathrm{C} / \mathrm{m}^{2}\right)$

$r \quad$ distance between the centers of two spherical particles

$V \quad$ volume of spherical particle $\quad\left(\mathrm{m}^{3}\right)$

$W_{(D) p l a n e}$ interactive free energy between the hemisphere and the flat plate
Greek

$\gamma_{1} \quad$ surface free energy of liquid $1 \quad\left(\mathrm{~J} / \mathrm{m}^{2}\right)$

$\gamma_{2} \quad$ surface free energy of liquid $2 \quad\left(\mathrm{~J} / \mathrm{m}^{2}\right)$

$\gamma_{12} \quad$ surface free energy of interface of liquid 1 and liquid 2

$\left(\mathrm{J} / \mathrm{m}^{2}\right)$

$\varepsilon_{0} \quad$ space permittivity $\left(\varepsilon_{0}=8.55 \times 10^{-12} \mathrm{~F} / \mathrm{m}\right) \quad(\mathrm{F} / \mathrm{m})$

$\theta$ angle between the electric field direction and the line connecting to the centers of two spherical particles $\left(^{\circ}\right)$

$\rho$ density of the particle $\left(\mathrm{kg} / \mathrm{m}^{3}\right)$

$\rho^{\prime} \quad$ average density of fluids $\quad\left(\mathrm{kg} / \mathrm{m}^{3}\right)$

$\sigma(a)$ surface tension of of the particle of the fluorescent powder at the boundary of two liquids $\quad\left(\mathrm{J} / \mathrm{m}^{2}\right)$

$\chi_{e} \quad$ polarizability $(-)$

\section{REFERENCES}

1) Otsuki, A., Matsuda M., Guangjun M., et.al, Recycling Fluorescent Powders Using Liquid-Liquid Extraction, Proceedings of International Symposium on Green Technology for Resources and Material Recycling, pp.100104, (2004).

2) Shinoya, S. and Yen, M.W. Eds., "Phosphor Handbook," CRC Press, pp.5-7, (1998).

3) Zhang, Q. and Saito, F., Non-thermal Extraction of Rare Earth Elements from Fluorescent Powder by Means of its Mechanochemical Treatment, J. Min. Mater. Process. Inst. Jpn., 114, 253-257, (1998) （in Japanese with English abstract).

4) Takahashi, T., Takano, A., Saito, T., Nagano, N, Hirai, S and Shimakage, K., Separation of Recovery of Rare Earth Elements from Phosphor Sludge in Processing Plant of Waste Fluorescent Lamp by Pneumatic Classification and Sulfuric Acidic Leaching, J. Min. Mater. Process. Inst. Jpn., 117, 579585, (2001) (in Japanese with English abstract).

5) Gaudin A.M.,"Flotation", McGRAW-HILL, pp.374-383, (1957).

6) Otsuki, A. et al., Recycling Fluorescent Powders Using Liquid-Liquid Extraction, Proceedings of Resources Recycling Technology-2005, 519-522, (2005).

7) Milling, A., et al., "Direct Measurement of Repulsive van der Waals Interactions Using an Atomic Force Microscope," J. Colloid Interface Sci., 180, 460-465 (1996).

8) Derjaguin, B.V., "Untersuchungen über die Reibung und Adhäsion, IV," Kolloid Zeits. Vol. 69, 155-164, (1934).

9) Antonov, G.N., "Sur la tension superficielle a la limite de deux couches", J. Chim. Physique, 5, 372-385, (1907).

10) Asahara, S., Ed., "Solvent Handbook", Kodan-Sha, pp.156158 and 734-738, (1976). 